\title{
Indoor air quality: an enviro-cultural perspective
}

\author{
O. E. Mansour \\ University of Calgary, Canada
}

\begin{abstract}
A healthy building seems to be desirable even if one does not know about its true implication on building occupants, performance, efficiency, productivity, cost, and maintenance. However, convincing a project's developer or building's owner about the merits of taking care of the indoor air quality is not as easy as most buildings' users think. This hardship is because the justification of the extra effort, time and resources needed for establishing a building with a higher level of indoor air quality is not as easy as many other building aspects. Architects and engineers can justify a higher price for stylish furniture, or better lighting design for a building's owner easier than justifying the cost of a system's add-ons needed for better indoor air quality. Studies show that some cultural dimensions are involved in the perception of the environmental risk, and hence impact the decision of having healthy buildings at the design stage. This paper analyzes the perception of the foreseeable extra cost and effort required for having a healthy building with a higher level of indoor air quality in light of the perception of the environmental risk and some other cultural factors. This empirical analysis is helpful for prospective developers and owners as it might be a great motivation for them to spend on enhancing the indoor air quality of their buildings. The argument is also critical for understanding the factors that lie behind the levels of indoor air quality in the built environment across cultures.
\end{abstract}

Keywords: indoor air quality, environmental risk, culture, healthy building, perception, decision making.

\section{Introduction}

For a long time, people have been describing the buildings that don't have an adverse effect on their health and wellbeing as healthy buildings. However, 
Spengler and Chen in 2000 stated that the concept of a healthy building is still polemic, with no consistent guidelines. It is important to recognize that, although indoor air quality (IAQ) is an important determinant of healthy design, it is not the sole determinant, as occupants experience the full sensory world. Other parameters include lighting, acoustics, vibration, aesthetics, comfort, and security, along with safety and ergonomic design factors [1]. Others defined sustainable building as healthy building [2]. In this article, rather than adopting the definition of a healthy building as a building, which provides its occupants with the maximum possible health, wellbeing and comfort, this includes physical comfort, functional comfort and psychological comfort [3] the author focuses on the IAQ as the key element of perceiving and feeling of a healthy building from building users' point of view. This conforms to some observations and empirical studies in which examined the definition of a healthy building in different cultures [1, 4]

Since building design and construction has moved toward the realm of sustainability, the debate about the benefits and costs of having healthy buildings didn't stop. Yet developers build projects for investing their capitals; while there are many other objectives might gain their attention when they decide on a sustainable project. When it comes to investment-related decisions for a new construction there often seems to be conflict of interests. Quite often, the intention of creating an attractive work environment, fulfilling ecological goals and being cost efficient are opposed, which can lead to long planning processes and increased project revisions. In the end, it is common for the investment decision to be made according to financial reasons, and other aspects like environmental and social considerations are then often sidelined [3]. Developer's objectives also differ based on the purpose of each project; sometimes they build commercial buildings to accommodate or serve their businesses, i.e. an investor build an office building for his company. In other cases they build projects to sell them to unknown customers. The decisions related to indoor air quality are mostly different in each case. When they build for their businesses they are always quite sure about their needs and what they want from the building. On the other hand, investors sometimes are myopic when the decisions come to environmental issues such as indoor air quality for a project they intend to sell after.

Even though the topic of sustainable construction is well known in the business, and widely discussed in research and practice, the additional investment and costs for healthy buildings seems to present an obstacle for the wider development of sustainable construction [3]. Although at the beginning of the human life man lived unsheltered, modern man nowadays spends most of his lifetime indoors. The time people spend indoors throughout their lives has a significant influence on their wellbeing, productivity and quality of life. This article analyzes the perception of the foreseeable extra cost and effort required for having a healthy building with higher level of indoor air quality in light of the perception of the environmental risk. 


\section{Indoor air quality}

Indoor air quality plays a key role in the indoor environmental quality [1]. Whether the indoor air quality determined by the properties of the air in terms of temperature, relative humidity, and the volumetric percentage of each component of the air or the amount of airborne contaminants transported by the air movement in and out of the organs of human body, the impact of indoor air quality on human health is confirmed. The major airborne contaminants are; Ozone, Carbon monoxide $(\mathrm{CO})$, Carbon dioxide $\left(\mathrm{CO}_{2}\right)$, Nitrogen dioxide $\left(\mathrm{NO}_{2}\right)$, Radon, Lead, Particulate matters, Environmental Tobacco Smoke (ETS), Volatile Organic Compounds (VOCs), Microbial Organic Compounds (MVOCs), and Biological Contaminants such bacteria and viruses.

Moreover, mold is one of the most dangerous air contaminants; exposure to certain fungi (molds) can cause human illness. Molds cause adverse human health effects through 3 specific mechanisms: generation of a harmful immune response, e.g. allergy or Hypersensitivity Pneumonitis (HP), direct infection by the organism and toxic-irritant effects from mold byproducts. For each of these defined pathophysiologic mechanisms, there are scientifically documented mold-related human diseases that present with objective clinical evidence of disease. Recently, in contrast to these well-accepted mold-related diseases, a number of new moldrelated illnesses have been hypothesized. This has become a particular issue in litigation that has arisen out of unproved assertions that exposure to indoor molds causes a variety of ill-defined illnesses. People who have asthma, bronchitis, hay fever, other allergies, or have weakened immune systems are more likely to react to mold. The most common symptoms are runny nose, eye irritation, skin rash, cough, congestion and aggravation of asthma. Symptoms usually disappear after mold exposure stops. Most often, there are no known long-term consequences to workplace exposures [5]. Therefore, laypeople perceptions of buildings that have higher level of indoor air quality still stem from the general their general feelings of air freshness and absence of smells and any complaints or adverse health effects.

\section{Perception of environmental risk across cultures}

Perception of the quality of environment and the level of potential environmental risk depends on many factors such as previous experience with environmental hazards in the place, how the culture considers the environment in the everyday life, level of education of people, the quality of life and the level of economy of the country. These factors have been long shared by researchers in perception of environmental hazards studies [4, 6-8]. Therefore it is reasonable to expect that factors differentiating individuals on the basis of shared experiences, values, and beliefs relevant to risk evaluation will be associated with non-equivalent perceptions in many situations [8].

Also, gender difference plays a significant role in the perception of the environmental risk. The survey done by Flynn et al. [4] shows that white women perceived risks to be much higher than did white men, a result that is consistent with previous studies. However, this gender difference was not true of non-white 
women and men, whose perceptions of risk were quite similar. These results suggest that socio-political factors such as power, status, alienation, and trust are strong determiners of people's perception and acceptance of risks. In another study, Chuk-ling Lai and Tao [6] suggest that Hong Kong Chinese tend to perceive environmental hazards as moderately threatening, which is consistent with prior findings from Zhang's (1994) study with PRC Chinese and Keown's (1989) study with Hong Kong Chinese.

\section{Extra cost, time, and effort associated with high level of IAQ}

Sustainable construction, which considered as healthy building with high level of indoor air quality, is often presumed as costly. Higher planning and material costs for sustainable construction are a major factor in the low share of sustainable buildings [3]. As part of sustainable design, higher level of indoor air quality in buildings seems to need additional effort and resources in design, construction, operation and maintenance phases. This potential of higher cost, extra time and effort is clear for most of stakeholders of any project. In the design phase, the project team might need an indoor air quality specialist to join them to discuss the available alternatives and set the criteria and standards needed for the project. These standards might add some extra cost in construction while additional sensors and monitoring equipment needed to monitor and alarm building users for the level of indoor air quality set by designers. The operation and maintenance needs not only the extra maintenance of indoor air quality monitoring equipment but also it add more cost due to the extra amount of fresh air required for ventilation that consume more energy on the HVAC system account.

Between the extra cost and effort required for having higher level of indoor air quality and the allocated budget for each building, a compelling justification needed to any developer or building owner to clarify why should we spend on this? Healthy buildings are very desirable from anyone; however when it comes to budget and investment, lots of questions arise to figure out what are the real benefits of making such features in a building? What are the environmental, social, and economic benefits of investing in indoor air quality in a building? Although the environmental revenue of having good indoor air quality in a building is understandable for most of people the environmental risk of having poor indoor air quality is still vague. Building occupants believe in the healthy outcomes of getting fresh air inside buildings for centuries, building owners also believe in a link between comfort, productivity and marketability, however, the implications of indoor air pollutants are not perceived as clear as the increase of the fresh air in the building through ventilation. Therefore, one can suggest that one of the cultural factors that affect the decision of having high level of indoor air quality in buildings is the information inherited or available for laypeople. The main reason for this shift between people's understanding of benefits and costs of having high and low levels of indoor air quality is education, specifically, the lack of environmental education which affects the sustainability of our planet [9]. 
In this context, it has to be mentioned that the link between having a sustainable building and cost is existed since the green building rating systems has been adopted by building industry. There are two main types of additional costs associated with obtaining eco-certification such as LEED or BREAM for commercial buildings: The first is the payments to the certifying body for rating the building. The second is the additional production costs associated with meeting the certification standards. In terms of the latter, there have been a number of studies of the construction cost premium associated with achieving certification. These studies suggest small construction cost premia of around $2 \%$ on average. The most recent and authoritative studies have come from Davis Langdon, a global construction consultancy [10].

Although the direct cost of achieving a high level of indoor air quality is clear for building designers and project owners, the indirect cost of poor indoor air quality is enormous and ambiguous. This indirect cost always appears when an incident of mold spreading or adverse health effects conducted by building occupants in a form of sick building syndrome accidentally noticed in a new or existing building. One of the most recent cases happened in the United States is the incident of the Grove apartment complex in Orono, Main. The project is located off Park Street about a half-mile from the Rangeley Road entrance to the University of Maine, the roughly $\$ 25.3$ million complex is made up of a dozen buildings with 12 apartments in each. When building occupants discover the symptoms of exposure to mold the owner, designers, and builder started to realize that there will be indirect or hidden cost for not taking care of the indoor air quality. Although town officials are satisfied that code requirements were met during the construction the mold and its health effects started to spread out in the apartments, the cost of remediating and fixing the affected parts exceeded a hundred thousand of US Dollars in addition to lowering the market value of the project.

\section{Potential benefits of having a higher indoor quality}

Healthy buildings have potential influence on building occupants; these influences can be in their health, wellbeing, and productivity. Productivity is usually described as the ratio of output to input $[3,11]$. Poor indoor air quality shows decreases in productivity as high as 6-9\% [12]. A study of doubling outdoor air supply has shown $10 \%$ reduction in illness and Improvement of work performance by approx. $1.5 \%$ [13]. Improved air quality (old carpets removed) shows improved performance, $20 \%$ lower dissatisfaction rate [14]. Increase outdoor clean air supply $6 \%$ performance improve [15]. Doubled air supply rate shows $35 \%$ lowered short-term sick leave [16]. In addition, healthy building concept provides the developer and shareholders with efficient buildings that need less maintenance than conventional structures. Long term maintenance of a healthy building is actually cost less than its counterpart conventional one, the building with higher level of indoor air quality has additional amount of fresh air to enter the building, it decreases the potential of mold growth and prevent sick building syndrome [3]. Employees near windows experience lower levels of sick building syndrome SBS 
symptoms than those located in building interiors - even though windows are not operable and thus the effect cannot be due to increased ventilation [17]

Building owners may think that some extra resources needed for higher Minimum Efficiency Rating Value MERV rate for the filtration media and higher frequency of replacing HVAC system filters, this is right, however, these extra resources will reduce the amount of air pollutants such as mold spores and biological contaminants from entering the building. A study compared 83 buildings with a primary goal of LEED certification with 138 similar building projects without the goal of sustainable design [18], Confirming the findings of earlier studies, they found no significant difference in average costs for building projects with a primary goal of LEED certification as compared to noncertified buildings [10]. The indoor air quality requirements might also add value to some other items like duct works and insulation selection and installation during construction. Most of mold problems come out of moisture that penetrates the building due to lack of good insulation, the indoor air quality plan might add more restrictions on the dump proof materials and how it is installed. A better work environment with an enhanced indoor environmental quality (IEQ) is leading to higher user satisfaction and thus increased financial paybacks. In a different study authors outline an example of an ideal loop for indirect monetary benefits [14].

Other financial incentives like tax reductions or public subsidies often attract individuals who are building their family houses and do not work for companies. Thus, at this point, sustainable features may not be profitable for investors unless there are other financial benefits. Such benefits could occur through capital and rental value premiums, higher occupancy rates, reduced operational costs or a reduced risk premium. Most of these points, however, also would not account for investors who are using the building as a means of their own needs and are not considering lunching their facilities for sale to the market. Such investment improves the IEQ, and as a result, the comfort and performance of the building users is also improved. Hence, the direct effect of a more sustainable property would not only be a better IEQ but, with measurable increases in productivity, would lead to financial benefits for the companies. Besides, these internal effects they also state that in the cases of building rentals, or possible sales, increased prices can be achieved [3].

The annual costs of energy and maintenance for running a heating, ventilating, and air-conditioning (HVAC) system and life-cycle costs (LCC) of investments for improving air quality in an office building were compared with the resulting revenues from increased office productivity as a consequence of improved worker performance; the air quality was improved by increasing the outdoor air supply rate and by reducing the pollution loads. These upgrades involved increased energy and HVAC costs. The annual benefit due to improved air quality was up to 115 times higher than the increase in annual energy and maintenance costs. LCC analysis shows that productivity benefits resulting from better indoor air quality were up to 60 times higher than the increased costs [19]. 


\section{Conclusion}

The decision making for having a building with higher level of indoor air quality is affected by three major factors; first is the perception of environmental risk, this factor is very sensitive to the project site in terms of the climate, the history of the place, the culture of people involved in the decision making and the culture of the prospective project occupants. Second factor is the extra effort needed to acquire the knowledge and hire a specialized consultant to support the project's team with the criteria of design for a building with higher indoor air quality. The third factor is the additional cost needed to implement a design that accommodate a high level of indoor air quality.

Decision Making

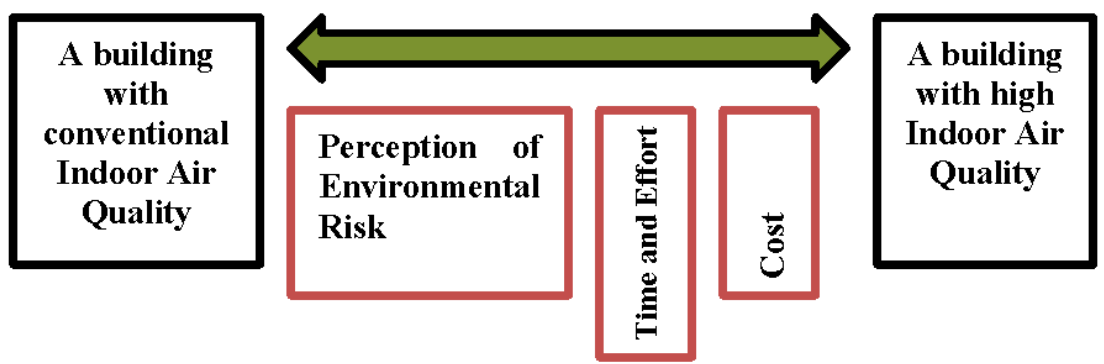

Figure 1: Factors affecting decision making of having a building with a higher level of indoor air quality.

Although the three factors are commonly perceived as environmental and financial factors, in the context of sustainable building design and healthy buildings they are sensitive to the social and cultural dimensions of people who are involved in each project. The author's central claim is that the cost, time, effort, and perception of environmental risk resulted from poor indoor air quality depend on the cultural differences and other human factors such as the previous experience of people involved in any project, even if some would think that the cost is independent from this continuum some studies shows that the spending on buildings could be explained as kind of consumer behaviour [20].

Although the cost of having a healthy building, which is now commonly defined as sustainable building, is higher than conventional building the demand on it is increasing every day. In 2011, in the US, there were approximately 24,000 Leadership in Energy and Environmental Design (LEED) certified residential and commercial buildings, (LEED homepage November 2011), which pale into insignificance when compared with the 1.8 million houses and 170,000 commercial buildings built each year in the USA [3, 21]. By 2013 the number of registered and certified LEED buildings exceeds 50,000 buildings (LEED homepage October 2013). Green Buildings provide financial benefits that 
conventional buildings do not. A recent report concludes that financial benefits of green design are between $\$ 50$ and $\$ 70$ per square foot in a LEED building, and this is almost over 10 times of the additional cost associated with green building design and construction. The financial benefits are in lower energy, waste and water costs, lower environmental and emissions costs, and lower operational and maintenance costs and increased productivity and health [22]. If we believe that the main objective of any building is achieving the maximum comfort for the occupants we should attest that having a healthy building is priceless as it saves cost of maintenance, reduce the absenteeism rate, and generate a more productive environment for building occupants.

\section{References}

[1] Spengler, J.D. and Q. Chen, Indoor air quality factors in designing a healthy building. Annual Review of Energy and the Environment, 2000. 25(1): pp. 567-600.

[2] Loftness, V., et al., Elements that contribute to healthy building design. Environmental Health Perspectives, 2007. 115(6): p. 965.

[3] Feige, A., et al., Impact of sustainable office buildings on occupant's comfort and productivity. Journal of Corporate Real Estate, 2013. 15(1): pp. 7-34.

[4] Flynn, J., P. Slovic, and C.K. Mertz, Gender, Race, and Perception of Environmental Health Risks. Risk Analysis, 1994. 14(6): pp. 1101-1108.

[5] Rapoport, A. and R.E. Kantor, Complexity and Ambiguity in Environmental Design. Journal of the American Institute of Planners, 1967. 33(4): pp. 210221.

[6] Chuk-ling Lai, J. and J. Tao, Perception of Environmental Hazards in Hong Kong Chinese. Risk Analysis, 2003. 23(4): pp. 669-684.

[7] Bruce, N., R. Perez-Padilla, and R. Albalak, Indoor air pollution in developing countries: A major environmental and public health challenge. World Health Organization. Bulletin of the World Health Organization, 2000. 78(9): pp. 1078-92.

[8] Vaughan, E. and B. Nordenstam, The Perception of Environmental Risks among Ethnically Diverse Groups. Journal of Cross-Cultural Psychology, 1991. 22(1): pp. 29-60.

[9] Orr, D.W., Earth in mind : on education, environment, and the human prospect. 1994, Washington: Island Press. ix, 213 p.

[10] Fuerst, F. and P. McAllister, Green Noise or Green Value? Measuring the Effects of Environmental Certification on Office Values. Real Estate Economics, 2011. 39(1): pp. 45-69.

[11] Oseland, N. and P. Bartlett, Improving office productivity. 1999: Longman.

[12] Wyon, D., The effects of indoor air quality on performance and productivity. Indoor air, 2004. 14(s7): pp. 92-101.

[13] Bornehag, C.-G., et al., The association between asthma and allergic symptoms in children and phthalates in house dust: a nested case-control study. Environmental health perspectives, 2004. 112(14): p. 1393. 
[14] Wargocki, P., et al., The effects of outdoor air supply rate in an office on perceived air quality, sick building syndrome (SBS) symptoms and productivity. Indoor Air, 2000. 10(4): pp. 222-236.

[15] Bakó-Biró, Z., et al., Effects of pollution from personal computers on perceived air quality, SBS symptoms and productivity in offices. Indoor air, 2004. 14(3): pp. 178-187.

[16] Milton, D.K., P.M. Glencross, and M.D. Walters, Risk of sick leave associated with outdoor air supply rate, humidification, and occupant complaints. Indoor Air, 2000. 10(4): pp. 212-221.

[17] Fisk, W.J. and A.H. Rosenfeld, Estimates of improved productivity and health from better indoor environments. Indoor air, 1997. 7(3): pp. 158-172.

[18] Fuerst, F. and P. McAllister, An investigation of the effect of eco-labeling on office occupancy rates. The Journal of Sustainable Real Estate, 2009. 1(1): pp. 49-64.

[19] Wargocki, P. and R. Djukanovic, Simulations of the Potential Revenue from Investment in Improved Indoor Air Quality in an Office Building. ASHRAE transactions, 2005. 111(2).

[20] Norman, D.A., Emotional design: why we love (or hate) everyday things. 2004, New York: Basic Books.

[21] Hoffman, A.J. and R. Henn, Overcoming the Social and Psychological Barriers to Green Building. 2008.

[22] Kats, G.H., Green Building Costs and Financial Benefits. Massachusetts Technology Collaborative, 2003. 